\title{
Visual Object Target Tracking Using Particle Filter: A Survey
}

\author{
G.Mallikarjuna Rao \\ Scientist 'E', DRDO (RCI), Andhra Pradesh, India \\ mallikarjun_rci@yhaoo.com \\ Dr. Ch.Satyanarayana \\ Professor \\ Department of Computer Science and Engineering \\ Jawaharlal Nehru Technological University Kakinada. Andhra Pradesh, India \\ chsatyanarayana@yahoo.com
}

\begin{abstract}
This paper gives the survey of the existing developments of Visual object target tracking using particle filter from the last decade and discusses the advantage and disadvantages of various particle filters. A variety of different approaches and algorithms have been proposed in literature. At present most of the work in Visual Object Target Tracking is focusing on using particle filter. The particle filters has the advantage that they deal with nonlinear models and non-Gaussian innovations, and they focus sequentially on the higher density regions of the state space, mostly parallelizable and easy to implement, so it gives a robust tracking framework, as it models the uncertainty and showing good improvement in the recognition performance compared to the kalman filter and other filters like Extended Kalman Filter (EKF), Unscented Kalman Filter (UKF).Various features and classifiers that are used with particle filter are given in this survey.
\end{abstract}

Index Terms - Kalman Filter, Extended Kalman Filter, Unscented Kalman Filter, Particle Filter, Visual Object Tracking

\section{INTRODUCTION}

From the last decade visual tracking of moving objects is an active area of research in computer vision. Recently particle filters have shown to be very suitable to perform real-time tracking applications. In the making of video surveillance systems "smart" requires fast, reliable and robust algorithms for moving object detection, classification, tracking and activity analysis. Moving object detection is the basic step for further analysis of video. Commonly used techniques for object detection are background subtraction, statistical models, temporal differencing. Object classification step categorizes detected objects into predefined classes such as human, vehicle, animal, clutter, etc. It is necessary to distinguish objects from each other in order to track and analyze their actions reliably.
The next step in the video analysis is tracking, which can be simply defined as the creation of temporal correspondence among detected objects from frame to frame. This procedure provides temporal identification of the segmented regions and generates cohesive information about the objects in the monitored area such as trajectory, speed and direction. The output produced by tracking step is generally used to support and enhance motion segmentation, object classification and higher level activity analysis.

The following briefly shows the three major categories of tracking methods[1]:

1) Point tracking: The target is expressed as a point in the frame, and the previous target state is utilized to make the association between targets and points. The Kalman filter is one of the famous trackers in this category.

2) Kernel tracking: Targets are tracked by computing the motion of the kernels which represent the appearance or shape of the targets. Mean shift tracker is a kind of kernel tracking.

3) Silhouette tracking: Given the target model, the target is tracked by estimating the region in each frame. For instance, contour matching and shape matching.

A filter is an algorithm that provides an efficient computational means to estimate the state of a dynamic system from a series of measurements. Filtering techniques can be used to improve model predictions by updating the model state variables sequentially i.e each time an observation is available [2].

A Kalman filter [3] is simply an optimal recursive data processing algorithm. There are many ways of defining optimal, dependent upon the criteria chosen to evaluate performance. It will be shown that, under the assumptions to be made in the next section, the Kalman filter is optimal with respect to virtually any criterion that makes sense. One aspect of this optimality is that the Kalman filter incorporates all information that can be provided to it. It processes all available measurements, 
regardless of their precision, to estimate the current value of the variables of interest, with use of (1) knowledge of the system and measurement device dynamics, (2) the statistical description of the system noises, measurement errors, and uncertainty in the dynamics models, and (3) any available information about initial conditions of the variables of interest. For example, to determine the velocity of an aircraft, one could use a Doppler radar or the velocity indications of an inertial navigation system, or the pilot and static pressure and relative wind information in the air data system. Rather than ignore any of these outputs, a Kalman filter could be built to combine all of this data and knowledge of the various systems' dynamics to generate an overall best estimate of velocity.

The real time functions are non-linear and all the systems can be represented as discrete time system to a great extent of accuracy using very small time steps. Now the problem is to estimate the states of this discrete-time controlled process and the process is generally expressed with the help of linear stochastic difference equation. This estimation can be easily and accurately done by the Kalman Filter. But when the process and the measurement systems are non-linear, EKF and UKF are implemented [4]. A KF that linearizes about the current mean and covariance using any linearzing function is called extended KF. In this the partial derivatives of the process as well as measurement functions are used to compute estimates in the presence of non-linear functions.

In the kernel tracking, moving objects are characterized by their color-histograms. Histogram estimation is the key operation of the object tracking algorithm. Mean-shift tracking algorithm is an iterative scheme based on comparing the histogram of the original object in the current image frame and histogram of candidate regions in the next image frame. The main aim is to maximize the correlation between two histograms[5].

Silhouette tracking is applied when tracking of the complete region of an object is required. Objects may have complex shapes, for example, hands, head, and shoulders that cannot be well described by simple geometric shapes. Silhouette based methods provide an accurate shape description for these objects[6].

This paper is organized as follows, in section II explains about the particle filter, Section III explains about the Visual object target tracking process using particle filter. Section IV gives about different features and classifiers that are used in visual objet target tracking with particle in the literature, Section $\mathrm{V}$ gives the comparison of Particle filters used for visual object tracking and this paper is summarized and concluded in section VI.

\section{PARTICLE FILTER}

Particle filter has been shown to offer improvements in performance over some conventional methods such as Kalman filter which are explained above, especially in non-linear or non-Gaussian environment. [7]. Particle filter has been extensively used in tracking multiple objects, employing visual (e.g. color, texture), geometric (e.g. contours, shape) and motion features[8] , econometrics, robotics and navigation.

Particle filter is a filtering method based on Monte Carlo and recursive Bayesian estimation. The particle filter, also known as condensation filter and they are suboptimal filters. The core idea is that density distribution is present using random sampling particles. There is no restriction to the state vector to deal with nonlinear and non-Gaussian problem, and it is the most general Bayesian approach. The working mechanism of particle filters is given as follows. The state space is partitioned as many parts, in which the particles are filled according to some probability measure. The higher probability, the denser the particles are concentrated. The particle system evolves along the time according to the state equation, with evolving pdf determined by the FPK equation. Since the pdf can be approximated by the point-mass histogram, by random sampling of the state space, we get a number of particles representing the evolving pdf.

The basic steps block diagram in particle filtering is shown below.

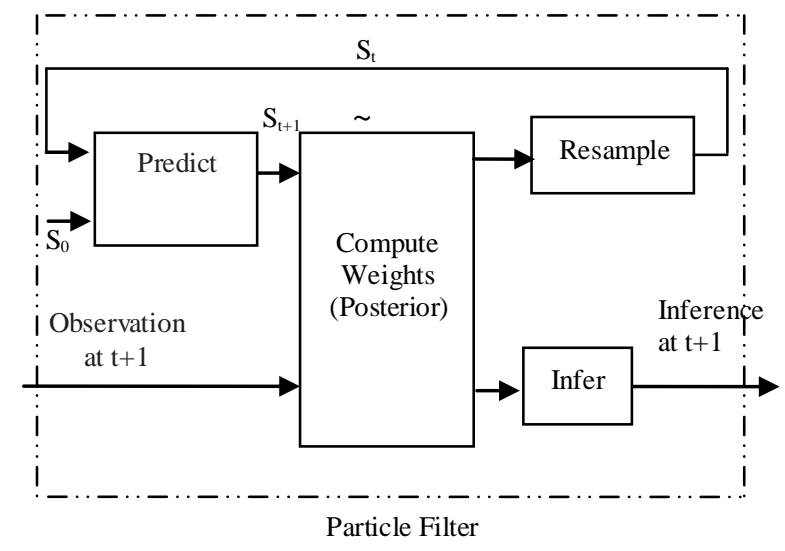

Figure 1: Generic Particle Filter Algorithm

The above Fig. 1 represents the particle filtering (PF) scheme. Consider a system whose state is changing in time $S_{t}=f\left(S_{t-1}, W_{t}\right)$ where $S_{t}$ is the system state at time $t$. The function $\mathrm{f}$ is called the state transition model and says that the system is Markovian. That is, $\mathrm{S}_{\mathrm{t}}$ depends on the previous state $\mathrm{S}_{\mathrm{t}-1}$ and the system (process) dynamics $\mathrm{W}_{\mathrm{t}}$, which enable the system to change in time. Also, assume the system is being partially observed using a set of noisy sensors $Z_{t}=h\left(S_{t}, V_{t}\right)$. Here $h$ is called the observation model and captures the relationship between the current system state $S_{t}$, the sensor observation $Z_{t}$, and sensor noise $\mathrm{V}_{\mathrm{t}}$. The randomness associated with $\mathrm{W}_{\mathrm{t}}$ and $\mathrm{V}_{\mathrm{t}}$ is assumed to be known and captured through pdfs [9]. 


\section{The Particle Filter steps:}

The algorithm has three major steps, namely selection, prediction, and measurement. Major steps in the algorithm are shown in Fig. 2.

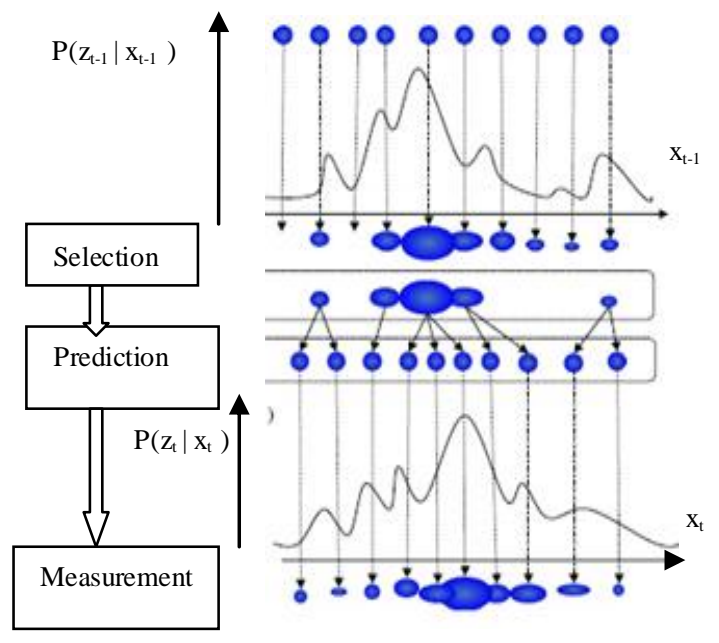

Figure 2: Particle filter algorithm

In the selection stage, we generate a new particle set by choosing the particles with the highest posterior probability among the previous particle set. The prediction step attempts to evaluate how the state of an object will change by feeding it through a dynamic model. The dynamic model serves two purposes: imposing deterministic drift to the state density and spreading the state density by stochastic diffusion[10]. During prediction, each particle is modified according to the state model, including the addition of random noise in order to simulate the effect of the noise on the state. In the measurement step, each particle's weight is reevaluated based on the new data, we estimate likelihood probability [11].

The particle filter in summery is given as following steps[12].

1. The system and measurement equations are given as follows:

$\mathrm{x}_{\mathrm{k}+1}=\mathrm{f}_{\mathrm{k}}\left(\mathrm{x}_{\mathrm{k}}, \mathrm{w}_{\mathrm{k}}\right)$

$\mathrm{y}_{\mathrm{k}}=\mathrm{h}_{\mathrm{k}}\left(\mathrm{x}_{\mathrm{k}}, \mathrm{v}_{\mathrm{k}}\right)$

where $X_{k}$ is the vector of the state variables at time $t$ computed using a function $f, \mathrm{w}_{\mathrm{k}}$ and $\mathrm{v}_{\mathrm{k}}$ are independent white noise processes with known pdf's. $Y_{k}$ is an observation related to $X_{k}$ by a function $h$.

2. Assuming that the pdf of the initial state $p\left(x_{0}\right)$ is known, randomly generate $\mathrm{N}$ initial particles on the basis of the pdf $\mathrm{p}\left(\mathrm{x}_{0}\right)$. These particles are denoted $\mathrm{x}_{0,1}+(\mathrm{i}=1, \ldots, \mathrm{N})$. The parameter $\mathrm{N}$ is chosen by the user as a tradeoff between computational effort and estimation accuracy

3. For $\mathrm{k}=1,2, \ldots$, do the following (a) Perform the time propagation step to obtain a priori particles $\mathrm{x}-\mathrm{k}$ using the known process equation and the known pdf of the process noise:

$\mathrm{x}_{\mathrm{k}, \mathrm{i}}^{-}=\mathrm{f}_{\mathrm{k}-1}\left(\mathrm{x}^{+}{ }_{\mathrm{k}-1, \mathrm{i}}, \mathrm{w}_{\mathrm{k}-1}^{\mathrm{i}}\right) \quad(\mathrm{i}=1, \ldots \mathrm{N})$

where each $\mathrm{w}_{\mathrm{k}-1}^{\mathrm{i}}$ noise vector is randomly generated on the basis of the known pdf Of $\mathrm{W}_{k-1}$.

b) Compute the relative likelihood qi of each particle

$\mathrm{x}_{\mathrm{k}, \mathrm{I}}$ and conditioned on the measurement $\mathrm{y}_{\mathrm{k}}$. This is done by evaluating the pdf $\mathrm{p}\left(\mathrm{y}_{\mathrm{k}} / \mathrm{x}_{\mathrm{k}, \mathrm{i}}\right)$ on the basis of the nonlinear measurement equation and the pdf of the measurement noise.

c) Scale the relative likelihoods obtained in the previous step as follows:

qi $=q \mathrm{i} / \sum \mathrm{Nj}=1$ qj

Now the sum of all the likelihoods is equal to one.

d) Generate a set of a posteriori particles $x+{ }_{k, i}$ on the basis of the relative likelihoods qi. This is called the resampling step.

e) Now that we have a set of particles $x+{ }_{k, i}$ that are distributed according to the pdf $\mathrm{p}\left(\mathrm{x}_{\mathrm{k}} / \mathrm{y}_{\mathrm{k}}\right)$, we can compute any desired statistical measure of this pdf. We typically are most interested in computing the mean and the covariance.

\section{PARTICLE FILTER FOR VISUAL TRACKING}

Visual tracking is an important problem with extensive application in domains including surveillance, behavior analysis, human-computer interaction and it has many increasing applications[13].Roughly, visual tracking algorithms can be divided into two main classes: deterministic tracking and stochastic tracking. Mean shift and particle filter are their typical representatives, respectively [14].Related to visual tracking, a particle filter uses multiple discrete "particle" to represent the belief distribution over the location of a tracked object. Particle filtering essentially combines the particles at a particular position into a single particle, giving that particle a weight to reflect the number of particles that were combined to form it. This eliminates the need to perform redundant computations without skewing the probability distribution. This will reduce the computational cost to reduce the number of samples that we analyze [15].

The basic block diagram for tracking visual objects using particle filter is shown in below Fig. 3 . 


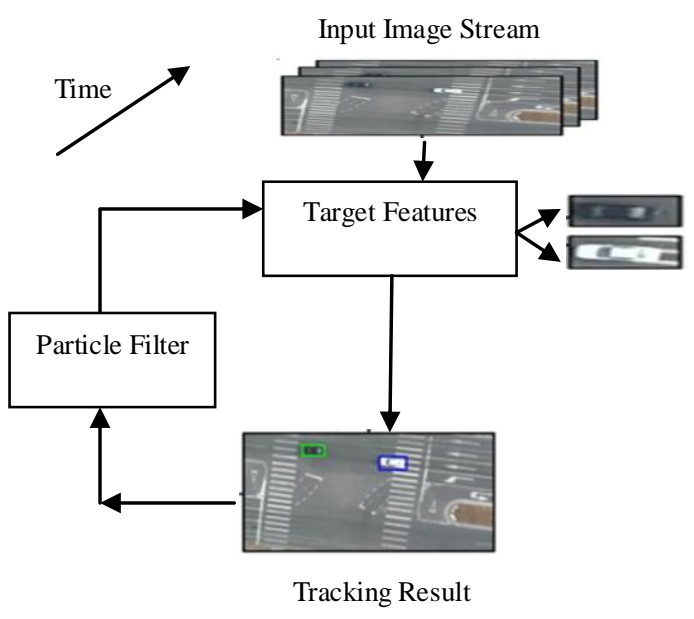

Figure 3: Visual Object Tracking Using Particle filter

The most important step of PF is the sequential importance sampling (SIS). A set of particles is produced at initial time, and then the importance weights are computed to seek the estimated value of state. But after several iterations for SIS, the weights of a majority of particles are ignored, leaving minority particles, perhaps even only a single particle[16].

The advantage of SIS is that it doesn't rely on the underlying Markov chain. The disadvantage of SIS is that we very easily encounter the situation that almost all the particles have zero weights and only a few of them (or only one) are non-zero. This importance weights may have large variances, resulting in inaccurate estimate. This is called the degeneracy problem in SIS filter.

SIS method can be also used in a non-Bayesian computation, such as evaluation of the likelihood function in the missing-data problem[17].

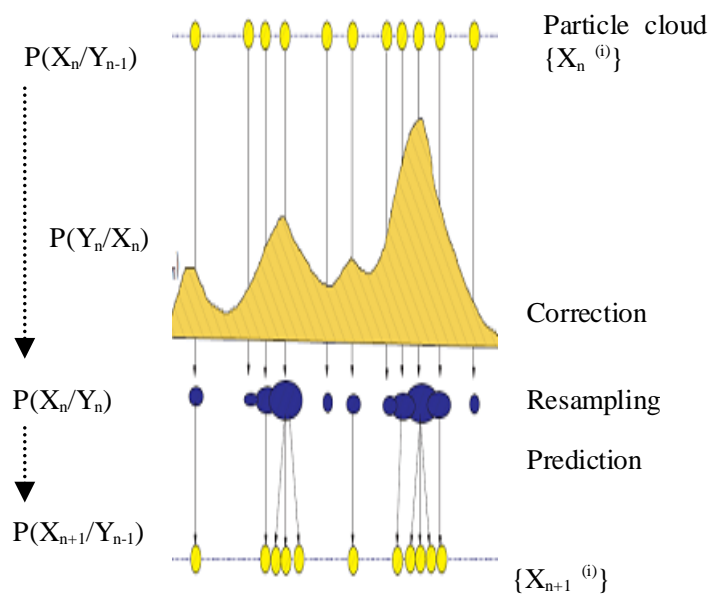

Figure 4: An illustration of generic particle filter with importance sampling and resampling

The versions of particles filters can be given as follows [17],[18]
1) SIR Filter (Bootstrap Filter)

2) Local Linearization Particle Filter

3) Interacting Multiple Model (IMM) Particle Filters

4) Auxiliary Particle Filter

5) Rejection Particle Filter

6) Rao-Blackwellization

7) Kernel Smoothing and Regularization

8) MCMC Particle Filter

9) Mixture Kalman Filter

10) Mixture Particle Filter.

11) Unscented Particle Filter

12) Boosted Particle Filter

Most of the above filters on derived based on SIS algorithm

\section{SIR Filter:}

Sequential importance resampling (SIR) is a generalization of the particle filtering framework, in which the resampling step is included as part of the sequential importance sampling algorithm[19].

The sampling-importance resampling (SIR) is motivated from the Bootstrap and jackknife techniques. Bootstrap technique is referred to a collection of computationally intensive methods that are based on resampling from the observed data. The performance of the SIR algorithm is depends on the quality of the importance distribution which is an approximation to posterior distribution of states given the values at the previous step.

The advantage of SIR filter is that importance weights are easily evaluated, substantial modularity, generality and importance density can be easily sampled [20].

The disadvantage of SIR is an "impoverishment" of the particle swarm is observed. It refers to the effect that when the noise in the dynamic model is very small, many of the particles in the particle set will turn out to have exactly the same value. The second drawback is if the posterior distribution has heavy tails (outliers happen), then a very large ensemble size is needed in order to represent these distant areas in phase space.

Both SIS and SIR filters use importance sampling scheme. The difference between them is that in SIR filter, the resampling is always performed (usually between two importance sampling steps), whereas in SIS filter, importance weights are calculated sequentially, resampling is only taken whenever needed, thus SIS filter is less computationally expensive.

To alleviate degeneracy problems many other methods have been proposed in literature like Local linearisation, Rejection methods, Auxiliary particle filters, Kernel smoothing, MCMC methods etc.

\section{Local Linearisation Particle Filter:}

Local linearization particle filter use banks of independent variants of Kalman filters to propose importance densities that are mindful of the latest measurement. 


\section{Interacting Multiple Model Particle Filter:}

The IMM uses multiple models for target behavior and adaptively determines which model(s) are the most appropriate at each time step. It characterizes a target as behaving according to one of M modes (e.g. stopped, moving with constant velocity, or accelerating). Each mode has an associated probability[21].

\section{Auxiliary Particle Filter:}

The auxiliary particle filter(APF) is a particle filtering algorithm introduced by Pitt and Shephard in 1999 to improve some deficiencies of the sequential importance resampling (SIR) algorithm when dealing with tailed observation densities[22]. The drawback is that the APF is computationally slower since the proposal is used twice. The drawbacks are not robust to outliers for two different reasons: sampling efficiency and the unreliability of the empirical prediction density in the tails of the distribution. The introduced auxiliary variable into the particle filter to overcome the above problems, providing a powerful framework that is as simple as SIR, but more flexible and reliable[23]. When the process noise is small, the performance of APF is usually better than that of SIR filter but when noise is large, the performance is not guaranteed.

\section{Rejection Particle Filter:}

Rejection particle is useful when we know the upper bound of underlying distribution or density. Rejection particle filter usually produces better results than SIR filter if the proposal distribution is appropriate.The drawback of rejection particle filter is that the computing time for every time step is fluctuating.

\section{Rao-Blackwellization:}

In pure recursive estimation the process noise is formally zero and thus a basic SIR based particle filter is likely to perform very badly. One way of improving the efficiency of SIR is to use Rao-Blackwellization. The main concept in this filter is decreasing number of particles necessary to achieve same accuracy with regular PF.

\section{MCMC Particle Filter:}

In the MCMC sampling framework, the samples are generated by a homogeneous, reversible, ergodic morkov chain with invariant distribution. This filter converges rapidly compared to the particle filter. The Markov Chain Monte Carlo (MCMC) sampling replaces the general resampling to prevent loss of diversity and to provide a resampling framework, which is amenable to pipeline processing[24].

\section{Mixture Kalman Filter :}

Mixture Kalman filter (MKF) can viewed as a special case of particle filter with marginalization and RaoBlackwellization on conditionally Gaussian linear dynamic model. The MKF uses the random mixture of normal distributions to represent a target distribution[25].The marginalization operation is employed to improve the efficiency is the main advantage of MKF.

\section{Kernel Smoothing and Regularization:}

These filters used an ad hoc approach called jittering to alleviate the sample impoverishment problem. In each time step, a small amount of Gaussian noise is added to each resampled particle, which is equivalent to using a Gaussian kernel to smooth the posterior.

\section{Mixture Particle Filter:}

The idea of Mixture Particle Filter (MPF) is similar to the stratified sampling and partitioned sampling idea, and includes the idea using EKF/UKF as Gaussian proposal approximation.

\section{Unscented Particle Filter:}

A particle filter with UKF importance distribution is also referred to as unscented particle filter (UPF).The conventional particle filter, e.g., CONDENSATION, uses transition prior as the proposal distribution. The transition prior does not take into account current observation data, and many particles can therefore be wasted in low likelihood area. To overcome these difficulties, unscented particle filter (UPF) has recently been proposed in the field of filtering theory[26].

\section{Boosted Particle Filter:}

In the standard particle filter, there are two major problems that need to be solved: the initialization of the particle filter and proper design of the importance proposal. The Boosted Particle Filter (BPF), properly solves the two problems by incorporating the AdaBoost detection algorithm[27].

\section{FEATURES USED IN VISUAL TARGET TRACKING USING THE PARTICLE FILTER}

In the visual object target tracking, many features are used for the best performance. Most of the features are given as follows,

1) Scale Invariant Feature Transform (SIFT)

2) Kanade Lucas Tomasi (KLT) features

3) Principal component analysis (PCA), kernel PCA

4) Independent Component Analysis (ICA)

5) Haar feature

6) Combined Mean-Shift

7) Geometric (e.g. contours (hand contours in case human hand tracking), shape)

8) Optical Flow, Local Feature, Edges, Lines, Size, Points, Planes, Edge Map, Orientation

9) Velocity, Visual (e.g. Color, Texture), Corner features, silhouette

10): SURF( Speeded up robust features )

11)Motion Feature (e.g. left hand turn with almost constant velocity, uniform acceleration, etc.)

12)Features from accelerated segment test (FAST)

13)RGB histogram, Edge Orientation Histogram, Local Binary Pattern (LBP) texture operator. 
The classifiers that are used mostly with particle filter in visual object tracking are given as follows

1. Nearest Neighbor Classifier

2. Hidden Markov Models

3. Neural Networks

4. Support Vector Machines

\section{COMPARISON OF PARTICLE FILTER METHODS FOR VISUAL OBJECT TRACKING}

The below table 1 gives the comparison of different particle filter algorithms for visual object tracking. Many versions of the particle filter are used. Different features are used to get the better tracking performance.

Table 1: Comparison of algorithms for visual object target tracking

\begin{tabular}{|c|c|c|c|}
\hline $\begin{array}{c}\text { SI.N } \\
\text { o. }\end{array}$ & Paper Title & Advantage & Remarks \\
\hline 1 & $\begin{array}{l}\text { Object Tracking with an Adaptive Color-Based } \\
\text { Particle Filter[28] }\end{array}$ & $\begin{array}{l}\text { The authors presented the integration of color } \\
\text { distributions into particle filtering and showed how } \\
\text { the distributions can be adapted over time. For the } \\
\text { similarity measure between two color distributions } \\
\text { the popular Bhattacharyya coefficient is applied in } \\
\text { this work. }\end{array}$ & $\begin{array}{l}\text { The proposed approach has real- } \\
\text { time capability but the processing } \\
\text { time is dependent on the region size } \\
\text { and the number of samples. In the } \\
\text { proposed approach, the tracker } \\
\text { might lose an object when it } \\
\text { changes appearance quickly. }\end{array}$ \\
\hline 2 & $\begin{array}{l}\text { Efficient Visual Tracking Using Particle } \\
\text { Filter[29] }\end{array}$ & $\begin{array}{l}\text { This paper presented a spatial color model of } \\
\text { object and authors developed an efficient visual } \\
\text { tracking algorithm based on particle filter. In order } \\
\text { to fast computation of the weight of each particle, } \\
\text { the Integral Images for computation of histogram, } \\
\text { mean and variance are proposed. }\end{array}$ & $\begin{array}{l}\text { The proposed algorithm has the } \\
\text { drawback of storage capacity is } \\
\text { relatively large. }\end{array}$ \\
\hline 3 & $\begin{array}{l}\text { Bayesian Filtering : From Kalman Filters to } \\
\text { Particle Filters, and Beyond VI Sequential } \\
\text { Monte Carlo Estimation : Particle Filters [17] }\end{array}$ & $\begin{array}{l}\text { The authors discussed Many variants of the } \\
\text { particle filter as well as their features (strengths } \\
\text { and weaknesses) and also Related theoretical and } \\
\text { practical issues are addressed in detail. }\end{array}$ & $\begin{array}{l}\text { This is a survey paper on different } \\
\text { filters based on Bayesian approach. }\end{array}$ \\
\hline 4 & $\begin{array}{l}\text { Visual contour tracking based on particle } \\
\text { filters }[30]\end{array}$ & $\begin{array}{l}\text { a Kalman particle filter (KPF) and an unscented } \\
\text { particle filter (UPF) are applied to contour } \\
\text { tracking. This proposed sampling strategy } \\
\text { effectively steered the set of particles towards } \\
\text { regions with high likelihood, and therefore it } \\
\text { considerably reduced the number of particles } \\
\text { needed for tracking. }\end{array}$ & $\begin{array}{l}\text { The UPF has a much higher } \\
\text { computational cost for equal } \\
\text { tracking error. }\end{array}$ \\
\hline 5 & Robust Visual Tracking for Multiple Targets [27] & $\begin{array}{l}\text { In this work, Hockey players are tracked and the } \\
\text { authors proposed four improvements on the } \\
\text { previous systems. By assembling all the } \\
\text { contributions, the new multi-target tracking system } \\
\text { are achieved the goal of tracking with good } \\
\text { performance. }\end{array}$ & $\begin{array}{l}\text { The drawback of the tracking } \\
\text { system is authors used the online } \\
\text { algorithm that reduced } \\
\text { performance. The system is also } \\
\text { sub-optimal. }\end{array}$ \\
\hline 6 & Visual Object Tracking Algorithms[31] & $\begin{array}{l}\text { The authors made a survey on visual tracking } \\
\text { algorithms which include kalman, ekf, ukf, particle } \\
\text { and vsmm estimation methods. }\end{array}$ & $\begin{array}{l}\text { All the algorithms are not fully } \\
\text { explained in the work. }\end{array}$ \\
\hline 7 & $\begin{array}{l}\text { Particle Filter based visual tracking with } \\
\text { multicue adaptive fusion [32] }\end{array}$ & $\begin{array}{l}\text { A novel tracking method based on adaptive fusion } \\
\text { and particle filter is proposed in this work. Image } \\
\text { cues and shape cues are used. The method is more } \\
\text { robust to illumination changes, pose variations, } \\
\text { particle occlusions, cluttered backgrounds and } \\
\text { camera motion. }\end{array}$ & $\begin{array}{l}\text { The image data base used for the } \\
\text { tracking is less. }\end{array}$ \\
\hline 8 & $\begin{array}{l}\text { Rao-Blackwellised Particle Filter for Tracking } \\
\text { with Application in Visual Surveillance [33] }\end{array}$ & $\begin{array}{l}\text { The authors exploited the analytical relationship } \\
\text { between state variables to improve the efficiency } \\
\text { and accuracy of a regular particle filter. Even in the } \\
\text { presence of reflections from the ground, the } \\
\text { opposing window, occlusion due to the text on the } \\
\text { window also the proposed algorithm shown good } \\
\text { performance. The no of particles required is also } \\
\text { very less. }\end{array}$ & $\begin{array}{l}\text { The proposed RBPF maintains } \\
\text { good estimation as long as the } \\
\text { dependency relationship falls into a } \\
\text { range around the true dependency } \\
\text { else it performance is less. }\end{array}$ \\
\hline 9 & $\begin{array}{l}\text { Improved Particle Filter in Sensor Fusion for } \\
\text { Tracking Randomly Moving Object [34] }\end{array}$ & $\begin{array}{l}\text { A new resampling algorithm is proposed to tackle } \\
\text { sample impoverishment, it utilized the adaptive } \\
\text { diversifying procedure to draw new particles from } \\
\text { the neighborhoods of the previously focused } \\
\text { resampled particles, approximating the posterior } \\
\text { distribution of the target state and it a real-time } \\
\text { algorithm to track a randomly moving object based } \\
\text { on information received from multiple sensors. }\end{array}$ & $\begin{array}{l}\text { The proposed algorithm tracking } \\
\text { fails when the tracking object } \\
\text { moves faster. It is giving good } \\
\text { performance only when the moving } \\
\text { object at a reasonable walking rate }\end{array}$ \\
\hline 10 & $\begin{array}{l}\text { Joint tracking algorithm using particle filter and } \\
\text { mean shift with target model updating [14] }\end{array}$ & $\begin{array}{l}\text { The main advantage of the mean shift and particle } \\
\text { filter (MSPF) is to sample fewer particles using } \\
\text { particle filter and then those particles are shifted to } \\
\text { their respective local maximum of target searching } \\
\text { space by mean shift. MSPF with model updating } \\
\text { shows good performance for color changes, similar } \\
\text { color appearance and cluttered backgrounds. }\end{array}$ & $\begin{array}{l}\text { The proposed MSPF loses the } \\
\text { tracked object when dealing with } \\
\text { the drastical change of the target } \\
\text { model and converge to a wrong } \\
\text { object with similar color to the } \\
\text { target model. }\end{array}$ \\
\hline
\end{tabular}




\begin{tabular}{|c|c|c|c|}
\hline 11 & $\begin{array}{l}\text { Non-overlapping Distributed Tracking System } \\
\text { Utilizing Particle Filter [35] }\end{array}$ & $\begin{array}{l}\text { The proposed a unified tracking framework using } \\
\text { particle filters to efficiently switch between visual } \\
\text { tracking (field of view tracking) and track } \\
\text { prediction (non-overlapping region tracking). The } \\
\text { proposed system utilizes a map (known } \\
\text { environment) to assist the tracking process when } \\
\text { targets leave the field of view of any camera. The } \\
\text { authors investigated the problem of tracking people } \\
\text { in a network of distributed camera system. }\end{array}$ & $\begin{array}{l}\text { This approach did not considered } \\
\text { the other pertinent issues like } \\
\text { background adaptation, crowded } \\
\text { scene tracking and object } \\
\text { interactions. }\end{array}$ \\
\hline 12 & $\begin{array}{l}\text { An integrated particle filter and potential field } \\
\text { method applied to cooperative multi-robot target } \\
\text { tracking }[36]\end{array}$ & $\begin{array}{l}\text { The proposed particle filter models a probability } \\
\text { distribution over the estimated location of the } \\
\text { target, providing robust tracking despite frequent } \\
\text { target occlusion. }\end{array}$ & $\begin{array}{l}\text { The main limitation of the method } \\
\text { is that it is essentially heuristic and } \\
\text { is not guaranteed to find optimal, or } \\
\text { indeed any, solutions. }\end{array}$ \\
\hline 13 & $\begin{array}{l}\text { An unscented particle filter for ground } \\
\text { maneuvering target tracking [37] }\end{array}$ & $\begin{array}{l}\text { The proposed method integrates the multiple } \\
\text { model (MM) filter with an unscented particle filter } \\
\text { (UPF) by an interaction step at the beginning. The } \\
\text { filtering method addresses nonlinear and/or non- } \\
\text { Gaussian tracking problems. }\end{array}$ & $\begin{array}{l}\text { The proposed method has more } \\
\text { computational complexity. }\end{array}$ \\
\hline 14 & $\begin{array}{l}\text { Real-time hand tracking using a mean shift } \\
\text { embedded particle filter [38] }\end{array}$ & $\begin{array}{l}\text { The authors incorporated the mean shift (MS) } \\
\text { optimization into particle filtering to move } \\
\text { particles to local peaks in the likelihood, the } \\
\text { proposed mean shift embedded particle filter } \\
\text { (MSEPF) improves the sampling efficiency } \\
\text { considerably. It proposed a simple but effective } \\
\text { approach for dynamic gesture recognition as it } \\
\text { used only color and motion cues. }\end{array}$ & $\begin{array}{l}\text { Other tracking problems, especially } \\
\text { the higher dimensional problems } \\
\text { such as 3D articulated object } \\
\text { tracking are not considered. }\end{array}$ \\
\hline 15 & $\begin{array}{l}\text { Rao-Blackwellized particle filter for multiple } \\
\text { target tracking [39] }\end{array}$ & $\begin{array}{l}\text { The proposed algorithm is based on formulating } \\
\text { probabilistic stochastic process models for target } \\
\text { states, data associations, and birth and death } \\
\text { processes. The tracking of these stochastic } \\
\text { processes is implemented using sequential Monte } \\
\text { Carlo sampling or particle filtering. }\end{array}$ & $\begin{array}{l}\text { The drawback of the proposed } \\
\text { approach is that the number of } \\
\text { particles increases with the number } \\
\text { of objects and also the } \\
\text { computational } \\
\text { increases. }\end{array}$ \\
\hline 16 & $\begin{array}{l}\text { A particle filter for joint detection and tracking } \\
\text { of color objects }[40]\end{array}$ & $\begin{array}{l}\text { The authors proposed a hybrid valued sequential } \\
\text { state estimation algorithm, and its particle filter- } \\
\text { based implementation, that extends the standard } \\
\text { color particle filter in two ways. the algorithm } \\
\text { handled the non-rigid deformation of targets, } \\
\text { partial occlusions and cluttered background. }\end{array}$ & $\begin{array}{l}\text { The main drawback of the proposed } \\
\text { approach is that the number of } \\
\text { particles increases with the number } \\
\text { of objects (i.e., the size of the state } \\
\text { vector). }\end{array}$ \\
\hline 17 & $\begin{array}{l}\text { Transductive local exploration particle filter for } \\
\text { object tracking [41] }\end{array}$ & $\begin{array}{l}\text { The authors applied a transductive inference to } \\
\text { update the target model dynamically. The proposed } \\
\text { transductive inference offers an effective way to } \\
\text { transduce object color model through the given } \\
\text { observations in non-stationary color distributions. }\end{array}$ & $\begin{array}{l}\text { Only color features is used for all } \\
\text { the experiments for testing. }\end{array}$ \\
\hline 18 & $\begin{array}{l}\text { Robust observation model for visual tracking in } \\
\text { particle filter [42] }\end{array}$ & $\begin{array}{l}\text { In this paper during tracking, the robust } \\
\text { observation model is incorporated in a particle } \\
\text { filter, and the particle filter can automatically select } \\
\text { proper appearance models to track object } \\
\text { according to the current tracking situation. The } \\
\text { proposed algorithm is able to track objects robustly } \\
\text { in the presence of illumination changes, large pose } \\
\text { variations, expression changes, and partial } \\
\text { occlusions. }\end{array}$ & $\begin{array}{l}\text { When the tracking object is moved } \\
\text { fast, the algorithm performance is } \\
\text { reduced. }\end{array}$ \\
\hline 19 & Motion Tracking Using Particle Filter[7] & $\begin{array}{l}\text { The authors developed a prototype to track a } \\
\text { bounce ball movement. The results are tested in } \\
\text { real time and the results are better than the kalman } \\
\text { filter. }\end{array}$ & $\begin{array}{l}\text { The processing time to track the } \\
\text { ball is more. }\end{array}$ \\
\hline 20 & $\begin{array}{l}\text { Multi-dimensional visual tracking using scatter } \\
\text { search particle filter [43] }\end{array}$ & $\begin{array}{l}\text { Authors proposed an algorithm which hybridizes } \\
\text { particle filters (PF) and the scatter search (SS) } \\
\text { metaheuristic, called scatter search particle filter } \\
\text { (SSPF), where the optimization strategies from SS } \\
\text { are embedded into the PF framework. }\end{array}$ & $\begin{array}{l}\text { The processing rate is less } \\
\text { compared to the other algorithms in } \\
\text { the proposed work. }\end{array}$ \\
\hline 21 & $\begin{array}{l}\text { Robust head tracking using 3D ellipsoidal head } \\
\text { model in particle filter [44] }\end{array}$ & $\begin{array}{l}\text { Proposed a particle filter framework for the robust } \\
3 \mathrm{D} \text { head tracking system that tracks the large } \\
\text { rotation and translation of the human head. }\end{array}$ & $\begin{array}{l}\text { The performance comparison is } \\
\text { done with few algorithms only. }\end{array}$ \\
\hline 22 & $\begin{array}{l}\text { Robust appearance-guided particle filter for } \\
\text { object tracking with occlusion analysis[45] }\end{array}$ & $\begin{array}{l}\text { Authors proposed a tracking algorithm based on } \\
\text { the robust appearance model which can account for } \\
\text { slow or rapid changes of object appearance. The } \\
\text { proposed algorithm invokes particle filter for state } \\
\text { estimation, thus making the tracker more robust } \\
\text { against occlusions and cluttered backgrounds. The } \\
\text { experimental tests involved many difficult } \\
\text { scenarios such as large pose variations, large } \\
\text { illumination changes, cluttered background and } \\
\text { severe occlusions. }\end{array}$ & $\begin{array}{l}\text { The performance measure is not } \\
\text { calculated for the algorithm. }\end{array}$ \\
\hline
\end{tabular}




\begin{tabular}{|c|c|c|c|}
\hline 23 & Particle filter tracking without dynamics[46] & $\begin{array}{l}\text { The proposed algorithm is based in particle filters, } \\
\text { but instead of using a dynamical model, it used } \\
\text { background subtraction to predict future locations } \\
\text { of particles. The algorithm is able to track people } \\
\text { in omni directional sequences with a low frame } \\
\text { rate (one or two frames per second). the proposed } \\
\text { approach can tackle unexpected discontinuities and } \\
\text { changes in the direction of the motion. The } \\
\text { proposed algorithm is especially useful in } \\
\text { situations where the frame rate is very low due to } \\
\text { physical restrictions on the system, bandwidth or } \\
\text { another processing. }\end{array}$ & $\begin{array}{l}\text { It works mainly in controlled } \\
\text { environments for example to track } \\
\text { people from laboratories etc. }\end{array}$ \\
\hline 24 & $\begin{array}{l}\text { Multiple object detection and tracking with } \\
\text { pseudo-particle filter }[47]\end{array}$ & $\begin{array}{l}\text { In this paper a pseudo particle filter (PPF), used in } \\
\text { which a multiple object data association and state } \\
\text { estimation technique is proposed to resolve the } \\
\text { subset particles correspondence ambiguities that } \\
\text { arise when multiple objects are present. It also } \\
\text { showed biological visual characteristic in some } \\
\text { extent. }\end{array}$ & $\begin{array}{l}\text { This paper solves the divergence } \\
\text { problems of the particle filter } \\
\text { algorithm with similar targets only. }\end{array}$ \\
\hline 25 & $\begin{array}{l}\text { A moving object tracking based on color } \\
\text { information employing a particle filter } \\
\text { algorithm }[48]\end{array}$ & $\begin{array}{l}\text { The authors used the color information and } \\
\text { considered the similarity between the color } \\
\text { histogram of the tracked object and the region } \\
\text { around the position of each particle. }\end{array}$ & $\begin{array}{l}\text { many aspects in tracking a moving } \\
\text { object that are not considered in the } \\
\text { proposed work. }\end{array}$ \\
\hline 26 & $\begin{array}{l}\text { CamShift guided particle filter for visual } \\
\text { tracking }[49]\end{array}$ & $\begin{array}{l}\text { A new algorithm is proposed, CamShift guided } \\
\text { particle filter (CAMSGPF), by exploring the } \\
\text { interaction between particle filtering and CamShift. } \\
\text { The execution time is also less for the proposed } \\
\text { algorithm. }\end{array}$ & $\begin{array}{l}\text { Accuracy should be compromised } \\
\text { if the time should be saved for the } \\
\text { proposed algorithm. }\end{array}$ \\
\hline 27 & $\begin{array}{l}\text { Face detection and tracking using a Boosted } \\
\text { Adaptive Particle Filter [50] }\end{array}$ & $\begin{array}{l}\text { The proposed algorithm is based on the synthesis } \\
\text { of an adaptive particle filtering algorithm and the } \\
\text { AdaBoost face detection algorithm. An Adaptive } \\
\text { Particle Filter (APF), based on a new sampling } \\
\text { technique is also proposed }\end{array}$ & $\begin{array}{l}\text { The tracking accuracy typically } \\
\text { reduces as the number of particles } \\
\text { in a particle filter decrease. }\end{array}$ \\
\hline 28 & $\begin{array}{l}\text { Tracking and recognizing actions of multiple } \\
\text { hockey players using the boosted particle } \\
\text { filter[51] }\end{array}$ & $\begin{array}{l}\text { Proposed a system that can automatically track } \\
\text { multiple hockey players and simultaneously } \\
\text { recognize their actions given a single broadcast } \\
\text { video sequence, where detection is complicated by } \\
\text { a panning, tilting, and zooming camera. Employed } \\
\text { the grids of Histograms of Oriented Gradients } \\
\text { (HOG) and the HSV color histogram as the } \\
\text { observation likelihood, and presented the } \\
\text { Switching Probabilistic Principal Component } \\
\text { Analysis (SPPCA) to model the appearance of the } \\
\text { players by a mixture of local subspaces. }\end{array}$ & $\begin{array}{l}\text { In the case of the Decomposed } \\
\text { Image Gradients (DIG) descriptor, } \\
\text { the accuracy of the Sparse } \\
\text { Multinomial Logistic Regression } \\
\text { (SMLR) classifier is significantly } \\
\text { poorer than the 5-NN classifier. }\end{array}$ \\
\hline 29 & $\begin{array}{l}\text { 2D Articulated Pose Tracking Using Particle } \\
\text { Filter with Partitioned Sampling and Model } \\
\text { Constraints[52] }\end{array}$ & $\begin{array}{l}\text { Proposed a partitioned sampling, applied to a new } \\
\text { articulated human body model and also proposed a } \\
\text { propagating method originated from belief } \\
\text { propagation (BP), which enables a set of particles } \\
\text { to carry several constraints. }\end{array}$ & $\begin{array}{l}\text { The tracking is failing in some test } \\
\text { conditions. }\end{array}$ \\
\hline 30 & $\begin{array}{l}\text { A color-based particle filter for multiple object } \\
\text { tracking in an outdoor environment [53] }\end{array}$ & $\begin{array}{l}\text { The authors proposed an approach to handle the } \\
\text { multiple-object tracking in the presence of } \\
\text { occlusions, background clutter, and changing } \\
\text { appearance. The occlusion is handled by } \\
\text { considering the predicted trajectories of the objects } \\
\text { based on a dynamic model and likelihood } \\
\text { measures. The algorithm successfully tracked } \\
\text { multiple objects in the presence of occlusion and } \\
\text { noise. }\end{array}$ & $\begin{array}{l}\text { The performance of multiple-object } \\
\text { tracking can be improved in several } \\
\text { ways, such as adding background } \\
\text { modeling information and so on. } \\
\text { Taking these factors into } \\
\text { consideration could lead to some } \\
\text { improvement. }\end{array}$ \\
\hline 31 & $\begin{array}{l}\text { Hybrid Blob and Particle Filter Tracking } \\
\text { Approach for Robust Object Tracking }[54]\end{array}$ & $\begin{array}{l}\text { This paper proposed a tracking system targeted for } \\
\text { real time surveillance tracking approaches so as to } \\
\text { exploit the advantages of both approaches while } \\
\text { minimizing their respective disadvantages. }\end{array}$ & $\begin{array}{l}\text { The proposed tracking approach } \\
\text { also suffers from some limitations } \\
\text { due to its assumption that the } \\
\text { occluded objects to be tracked by } \\
\text { employing top down approach must } \\
\text { be appeared as separate objects } \\
\text { before merged. }\end{array}$ \\
\hline 32 & $\begin{array}{l}\text { Mice and larvae tracking using a particle filter } \\
\text { with an auto-adjustable observation model }[8]\end{array}$ & $\begin{array}{l}\text { The authors proposed a novel way to combine } \\
\text { different observation models in a particle filter } \\
\text { framework. This is called, auto-adjustable } \\
\text { observation model, enhance the particle filter } \\
\text { accuracy when the tracked objects overlap without } \\
\text { infringing a great runtime penalty to the whole } \\
\text { tracking system. }\end{array}$ & $\begin{array}{l}\text { The processing speed is slight more } \\
\text { than the normal methods. }\end{array}$ \\
\hline
\end{tabular}




\begin{tabular}{|c|c|c|c|}
\hline 33 & $\begin{array}{l}\text { 3D human motion tracking based on a } \\
\text { progressive particle filter [55] }\end{array}$ & $\begin{array}{l}\text { This paper presented a novel 3D model-based } \\
\text { tracking algorithm (the progressive particle filter) } \\
\text { to decrease the computational cost in high degrees } \\
\text { of freedom by employing hierarchical searching. } \\
\text { The embedded mean shift trackers are adopted to } \\
\text { increase accuracy by moving each particle toward } \\
\text { the location with the highest probability of posture } \\
\text { through the estimated mean shift vector. }\end{array}$ & $\begin{array}{l}\text { In this work, the errors may be } \\
\text { caused when the predicted particles } \\
\text { are not located at the correct } \\
\text { position, or the number of particles } \\
\text { is not large enough to predict the } \\
\text { complete plausible angle for the } \\
\text { particle filter. }\end{array}$ \\
\hline 34 & $\begin{array}{l}\text { Modified particle filter-based infrared pedestrian } \\
\text { tracking }[56]\end{array}$ & $\begin{array}{l}\text { The authors proposed a modified particle filter } \\
\text { algorithm that combines intensity and edge cues } \\
\text { and also an automatic model updating strategy is } \\
\text { presented to increase tracking performance further. }\end{array}$ & $\begin{array}{l}\text { The implemented speed of the } \\
\text { proposed method is lower than that } \\
\text { of the traditional particle filter } \\
\text { method. }\end{array}$ \\
\hline 35 & $\begin{array}{l}\text { Particle filter based on Particle Swarm } \\
\text { Optimization resampling for vision tracking [57] }\end{array}$ & $\begin{array}{l}\text { In this paper, authors proposed an efficient } \\
\text { resampling method based on Particle Swarm } \\
\text { Optimization and found the sample area by PSO } \\
\text { algorithm, then distributed the particles based on } \\
\text { two different base points in order to achieve } \\
\text { diversity and convergence. }\end{array}$ & $\begin{array}{l}\text { In this work, the tracking may fail } \\
\text { when using the HOGC feature, } \\
\text { because of the illusive large weight } \\
\text { particles. }\end{array}$ \\
\hline 36 & $\begin{array}{l}\text { Interacting MCMC particle filter for tracking } \\
\text { maneuvering target [58] }\end{array}$ & $\begin{array}{l}\text { The proposed algorithm uses the particles that are } \\
\text { sampled from the target posterior distribution via } \\
\text { direct interacting MCMC sampling method, which } \\
\text { avoids sample impoverishment and increases the } \\
\text { robustness of the algorithm. The proposed } \\
\text { algorithm propagates each particle based on both } \\
\text { its history information and the information from } \\
\text { other particles. }\end{array}$ & $\begin{array}{l}\text { The authors observed the failure of } \\
\text { the tracking is due to sample } \\
\text { impoverishment. }\end{array}$ \\
\hline 37 & $\begin{array}{l}\text { A parallel histogram-based particle filter for } \\
\text { object tracking on SIMD-based smant } \\
\text { cameras[59] }\end{array}$ & $\begin{array}{l}\text { A parallel particle filter is employed with simple } \\
\text { color histograms as well as more complex } \\
\text { histograms of oriented gradients (HOG). PETS } \\
2001 \text { data set is used for testing. }\end{array}$ & $\begin{array}{l}\text { The target models are not updated. } \\
\text { So the algorithms are not robust to } \\
\text { large variations in the appearance } \\
\text { of the target. }\end{array}$ \\
\hline 38 & $\begin{array}{l}\text { Real-Time Camera Tracking for Structured } \\
\text { Environment Using an Iterated Particle } \\
\text { Filter }[60]\end{array}$ & $\begin{array}{l}\text { The proposed approach utilizes a 3D straight-line } \\
\text { based model of a structured environment. The } \\
\text { principal novelty is in the use of the 2D edges from } \\
\text { the image and the 3D lines from the input model } \\
\text { within the particle filter, especially to design the } \\
\text { likelihood function of the filter observation model. }\end{array}$ & $\begin{array}{l}\text { In this work, the authors found } \\
\text { processing time strongly depends } \\
\text { on two parameters, the number of } \\
\text { particles used in the estimation and } \\
\text { the tolerance threshold which } \\
\text { define the convergence criteria for } \\
\text { stopping iteration. }\end{array}$ \\
\hline 39 & $\begin{array}{l}\text { An Efficient Multiple Cues Synthesis for Human } \\
\text { Tracking using a Particle Filtering } \\
\text { Framework[61] }\end{array}$ & $\begin{array}{l}\text { The authors combined multiple cues(Spatial Color } \\
\text { Information ,Distance Transform image and Multi- } \\
\text { part Histogram) approach to get the better } \\
\text { performance. }\end{array}$ & $\begin{array}{l}\text { The proposed system is suitable } \\
\text { mainly to single object tracking for } \\
\text { example humans. }\end{array}$ \\
\hline 40 & $\begin{array}{l}\text { Tracking With a Hierarchical Partitioned } \\
\text { Particle Filter and Movement Modelling[62] }\end{array}$ & $\begin{array}{l}\text { The algorithm tracks human subjects in video } \\
\text { sequences using likelihoods adapted to the } \\
\text { hierarchical process. }\end{array}$ & $\begin{array}{l}\text { The proposed HPPF-MCM, similar } \\
\text { to other trackers, is the need for } \\
\text { several tuning parameters, so that } \\
\text { optimal performance can only be } \\
\text { achieved if these are well defined. }\end{array}$ \\
\hline 41 & $\begin{array}{l}\text { Improved Rao-Blackwellized particle filter for } \\
\text { simultaneous robot localization and person- } \\
\text { tracking with single mobile sensor[63] }\end{array}$ & $\begin{array}{l}\text { A Rao-Blackwellized particle filter based } \\
\text { algorithm was proposed to improve adaptive } \\
\text { resampling scheme, distribution optimization, and } \\
\text { extension to nonlin- ear dynamic system using } \\
\text { unscented Kalman filter.The algorithm is highly } \\
\text { computational efficient. }\end{array}$ & $\begin{array}{l}\text { A long term occlusions may still } \\
\text { lead to the failure of the tracking } \\
\text { method, so a strategy that searches } \\
\text { for the target person and } \\
\text { reinitializes the UKF based tracker } \\
\text { was to be implemented in real } \\
\text { environment applications. }\end{array}$ \\
\hline 42 & $\begin{array}{l}\text { A Robust Particle Filter-Based Method for } \\
\text { Tracking Single Visual Object Through } \\
\text { Complex Scenes Using Dynamical Object Shape } \\
\text { and Appearance Similarity[64] }\end{array}$ & $\begin{array}{l}\text { The authors employed a fully tunable rectangular } \\
\text { bounding box described by five parameters (2D } \\
\text { central location, width, height, and orientation) and } \\
\text { full functionaries in the joint tracking scheme. The } \\
\text { proposed method is robust in terms of tracking drift, } \\
\text { tightness and accuracy of tracked bounding boxes, } \\
\text { especially in scenarios where the target object } \\
\text { contains long-term partial occlusions, intersections, } \\
\text { severe deformation, pose changes, or cluttered } \\
\text { background with similar color distributions }\end{array}$ & $\begin{array}{l}\text { The proposed scheme is somewhat } \\
\text { sensitive to pose changes of large } \\
\text { objects. } \\
\text { The performance of the tracker also } \\
\text { somewhat degrades if there is a } \\
\text { long-duration of partial object } \\
\text { occlusion over a large area. }\end{array}$ \\
\hline 43 & $\begin{array}{l}\text { Tracking dynamic textures using a particle filter } \\
\text { driven by intrinsic motion information [65] }\end{array}$ & $\begin{array}{l}\text { The proposed algorithm has novelty is to use a } \\
\text { particle filter driven by the intrinsic motion of the } \\
\text { tracked dynamic texture. The algorithm is fast and } \\
\text { is able to track a dynamic texture moving on } \\
\text { another dynamic texture with different intrinsic } \\
\text { dynamics. }\end{array}$ & $\begin{array}{l}\text { The proposed method is also able to } \\
\text { track a dynamic texture in cases } \\
\text { where classical particle filters based } \\
\text { on color information only fail. }\end{array}$ \\
\hline 44 & $\begin{array}{l}\text { A particle filter-based approach for tracking } \\
\text { undersea narrow telecommunication cables [66] }\end{array}$ & $\begin{array}{l}\text { The proposed approach is based on particle filters } \\
\text { (PFs) because of their natural ability to model } \\
\text { multi-dimensional multi-modal PDFs, which } \\
\text { allows handling in a more appropriate way the } \\
\text { ambiguities that naturally arise from undersea } \\
\text { environments. }\end{array}$ & $\begin{array}{l}\text { There is not a clear benefit on the } \\
\text { average behavior of the cable } \\
\text { tracker when the number of } \\
\text { particles is increased. }\end{array}$ \\
\hline
\end{tabular}




\begin{tabular}{|c|c|c|c|}
\hline 45 & $\begin{array}{l}\text { Rao-Blackwellised particle filter for colour } \\
\text { based tracking [67] }\end{array}$ & $\begin{array}{l}\text { The authors proposed a method which estimates } \\
\text { jointly the location and shape of the target as well } \\
\text { as the appearance parameters. Rao-Blackwellised } \\
\text { particle filter allows us to combine both } \\
\text { estimations in a unique framework. The proposed } \\
\text { method has been proved more robust against } \\
\text { sudden illumination changes than methods in the } \\
\text { literature. }\end{array}$ & $\begin{array}{l}\text { The proposed methodology is } \\
\text { computationally more expensive } \\
\text { than classical updates. }\end{array}$ \\
\hline 46 & $\begin{array}{l}\text { Dimensionality reduction using a Gaussian } \\
\text { Process Annealed Particle Filter for tracking } \\
\text { and classification of anticulated body } \\
\text { motions }[68]\end{array}$ & $\begin{array}{l}\text { The authors introduced a body pose tracker that } \\
\text { uses the learned mapping function from latent } \\
\text { space to body pose space. }\end{array}$ & $\begin{array}{l}\text { The number of particles used in the } \\
\text { proposed approach is more and also } \\
\text { the method is capable of tracking } \\
\text { multiple subjects, the results are } \\
\text { much less accurate and the tracker } \\
\text { less robust than for the one person } \\
\text { case. }\end{array}$ \\
\hline 47 & $\begin{array}{l}\text { An evolutionary particle filter with the immune } \\
\text { genetic algorithm for intelligent video target } \\
\text { tracking[69] }\end{array}$ & $\begin{array}{l}\text { The proposed algorithm has particle set optimized } \\
\text { by immune genetic algorithm (IGA) can better } \\
\text { express the true state of the target, and the number } \\
\text { of meaningful particles can be increased } \\
\text { significantly and also it is better in particle } \\
\text { diversity, the error of state estimation, error } \\
\text { tracking of video, the number of meaningful } \\
\text { particles and efficiency. }\end{array}$ & $\begin{array}{l}\text { Performance is less in occlusions in } \\
\text { complex and dynamic changing } \\
\text { environment }\end{array}$ \\
\hline 48 & $\begin{array}{l}\text { A Robust approach for multiple vehicles } \\
\text { tracking using layered particle filter[16] }\end{array}$ & $\begin{array}{l}\text { Authors proposed a layered particle filter } \\
\text { architecture embedding continuous adaptive mean } \\
\text { shift, which considers both concentration and } \\
\text { diversity of particles, and the particle set can better } \\
\text { represent the posterior probability density. The } \\
\text { proposed approach works better at night times. }\end{array}$ & $\begin{array}{l}\text { Although CamShift guided particle } \\
\text { filter (CAMSGPF) tracker can track } \\
\text { targets correctly, after occlusion is } \\
\text { vanished, it also makes some error } \\
\text { when occlusion happens. }\end{array}$ \\
\hline 49 & $\begin{array}{l}\text { Heuristic particle filter: applying abstraction } \\
\text { techniques to the design of visual tracking } \\
\text { algorithms[70] }\end{array}$ & $\begin{array}{l}\text { Authors proposed a general framework to } \\
\text { hybridize heuristics/metaheuristics with particle } \\
\text { filters properly. The task is to devise effective } \\
\text { hybrid visual tracking algorithms naturally, guided } \\
\text { by the use of abstraction techniques. The proposed } \\
\text { algorithms exploited the benefits of both } \\
\text { complementary approaches to give the better } \\
\text { tracking performance. The proposed approach } \\
\text { takes less computation time than the PF and GPF } \\
\text { (Gaussian Particle Filter). }\end{array}$ & $\begin{array}{l}\text { The number of evaluations for the } \\
\text { memetic algorithm particle filter } \\
\text { (MAPF) remains almost constant } \\
\text { when the complexity of the } \\
\text { tracking problem increases. }\end{array}$ \\
\hline 50 & $\begin{array}{l}\text { Contour tracking using Gaussian particle } \\
\text { filter }[10]\end{array}$ & $\begin{array}{l}\text { In this paper, a sampling method combines } \\
\text { sampling step with prediction step by taking } \\
\text { advantage of the Gaussian assumption and by } \\
\text { exploring the linear structure of the system } \\
\text { dynamic model is proposed. }\end{array}$ & $\begin{array}{l}\text { The GPF contour tracker performs } \\
\text { poorly, when experiencing } \\
\text { significant rotation drift off the } \\
\text { target objects. }\end{array}$ \\
\hline 51 & $\begin{array}{l}\text { 3D Head Pose Tracking Using a Particle Filter } \\
\text { with Nose Template Matching [71] }\end{array}$ & $\begin{array}{l}\text { The authors proposed a method for fast and } \\
\text { accurate estimation of the driver's head pose that } \\
\text { each hypothesis is updated by prior probability } \\
\text { with the constraint of the nose position. Thus, it is } \\
\text { possible to reduce the number of particles while } \\
\text { maintaining accuracy and this method is effective } \\
\text { for head pose tracking. The proposed method } \\
\text { performs better in terms of both noise and } \\
\text { deviations. }\end{array}$ & $\begin{array}{l}\text { In this proposed work, more } \\
\text { cameras are needed for the } \\
\text { algorithm. }\end{array}$ \\
\hline 52 & $\begin{array}{l}\text { High performance memetic algorithm particle } \\
\text { filter for multiple object tracking on modern } \\
\text { GPUs }[72]\end{array}$ & $\begin{array}{l}\text { In this paper, authors proposed a particle filter (PF) } \\
\text { hybridized with a memetic algorithm (MA) to } \\
\text { produce a MAPF tracking algorithm for single and } \\
\text { multiple object tracking problems. }\end{array}$ & $\begin{array}{l}\text { The proposed method itself is } \\
\text { unable to track under heavy noise } \\
\text { or uncertainty, such as occlusions } \\
\text { or varying lighting conditions. }\end{array}$ \\
\hline 53 & $\begin{array}{l}\text { Visual Object Servo Tracking Based on the } \\
\text { Particle Filter Method Using a Pan-Tilt-Zoom } \\
\text { Camera[73] }\end{array}$ & $\begin{array}{l}\text { Authors proposed a closed loop control model } \\
\text { based on speed regulation to drive the Pan Tilt } \\
\text { Zoom (PTZ) camera to keep the target at the centre } \\
\text { of the camera angle which gave the tracking } \\
\text { performance much better than the other methods. }\end{array}$ & $\begin{array}{l}\text { Only a specific type of camera is } \\
\text { used in the proposed work. }\end{array}$ \\
\hline 54 & $\begin{array}{l}\text { Robust Visual Tracking Via MCMC-Based } \\
\text { Particle Filtering[74] }\end{array}$ & $\begin{array}{l}\text { The authors proposed MCMC-based particle } \\
\text { algorithm is proposed to estimate the posterior } \\
\text { distribution of the target state to solve the tracking } \\
\text { problem. }\end{array}$ & $\begin{array}{l}\text { The number of particles used in the } \\
\text { algorithm are more. }\end{array}$ \\
\hline 55 & $\begin{array}{l}\text { Application of particle filtering in visual } \\
\text { tracking[75] }\end{array}$ & $\begin{array}{l}\text { In this paper, authors introduced the application of } \\
\text { particle filtering in visual tracking and various } \\
\text { approaches on it. }\end{array}$ & $\begin{array}{l}\text { No experimental results are given } \\
\text { in the paper. }\end{array}$ \\
\hline
\end{tabular}




\begin{tabular}{|c|c|c|c|}
\hline 56 & $\begin{array}{l}\text { A Framework for 3D Model-Based Visual } \\
\text { Tracking Using a GPU-Accelerated Particle } \\
\text { Filter[76] }\end{array}$ & $\begin{array}{l}\text { The authors proposed a framework that addressed } \\
\text { the computational intensity that is intrinsic to all } \\
\text { particle filter approaches, including those that have } \\
\text { been modified to minimize the number of particles } \\
\text { required for a particular task. The proposed GPU } \\
\text { mapping could be adapted to support to an } \\
\text { alternative feature extractor, state estimation } \\
\text { technique, or particle filtering algorithm, as } \\
\text { dictated by an application's requirements. }\end{array}$ & $\begin{array}{l}\text { In this work, the performance } \\
\text { limitations on the GPU are } \\
\text { primarily consequences of warp } \\
\text { divergence necessitated by the edge } \\
\text { detection algorithm, such as the } \\
\text { padding of memory structures prior } \\
\text { to filter convolution. }\end{array}$ \\
\hline 57 & $\begin{array}{l}\text { Particle Filter With a Mode Tracker for Visual } \\
\text { Tracking Across Illumination Changes[77] }\end{array}$ & $\begin{array}{l}\text { The main advantage in the proposed method is to } \\
\text { importance sample on the motion states while } \\
\text { approximating importance sampling by posterior } \\
\text { mode tracking for estimating illumination. The } \\
\text { authors also detected illumination model changes, } \\
\text { e.g., those due to transition from shadow to } \\
\text { sunlight or vice versa by using the generalized } \\
\text { expected log-likelihood statistics and successfully } \\
\text { compensate for it without ever loosing track. }\end{array}$ & $\begin{array}{l}\text { In some test cases, the proposed } \\
\text { algorithm performance is cannot be } \\
\text { compared with other algorithms. }\end{array}$ \\
\hline 58 & $\begin{array}{l}\text { An Optimization-Based Parallel Particle Filter } \\
\text { for Multitarget Tracking[78] }\end{array}$ & $\begin{array}{l}\text { The authors proposed optimal scheduling, } \\
\text { mapping, and load balancing algorithm for parallel } \\
\text { particle filter that reduces the total execution time } \\
\text { of multitarget particle filters. Also, they proposed } \\
\text { an algorithm that is capable of handling } \\
\text { heterogenous processors and a varying number of } \\
\text { targets. The proposed algorithm requires } \\
\text { significantly less communication among the } \\
\text { processors, and it was proposed together with a } \\
\text { load scheduling and balancing algorithm. }\end{array}$ & $\begin{array}{l}\text { In some test cases, Because of the } \\
\text { approximation resulting from the } \\
\text { independent resampling at local } \\
\text { nodes, the local distributed particle } \\
\text { filter (LDPF') performance is } \\
\text { worse than that of the serial particle } \\
\text { filter. }\end{array}$ \\
\hline 59 & $\begin{array}{l}\text { An Efficient Particle Filter - based Tracking } \\
\text { Method Using Graphics Processing Unit } \\
\text { ( GPU )[79] }\end{array}$ & $\begin{array}{l}\text { Authors proposed an efficient particle filter-based } \\
\text { tracking algorithm using color information. The } \\
\text { authors developed parallel algorithms on a desktop } \\
\text { Graphics Processing Unit (GPU), which } \\
\text { accomplished the integral images construction and } \\
\text { cooccurrence histogram computation after bin } \\
\text { index determination which improved the } \\
\text { performance. }\end{array}$ & $\begin{array}{l}\text { Only one measurement model is } \\
\text { implemented in this proposed work. }\end{array}$ \\
\hline 60 & $\begin{array}{l}\text { Object tracking by exploiting adaptive region- } \\
\text { wise linear subspace representations and } \\
\text { adaptive templates in an iterative particle } \\
\text { filter }[80]\end{array}$ & $\begin{array}{l}\text { A higher tracking accuracy is achieved in this } \\
\text { work, by aggregating the good hypothetic } \\
\text { estimates from particles and also authors proposed } \\
\text { the adaptive mechanism to continuously adjust the } \\
\text { object templates so that the varying appearances of } \\
\text { tracked objects can be well handled. The proposed } \\
\text { algorithm shown good results on tracking objects } \\
\text { undergoing various pose changes, partial } \\
\text { occlusions, and illumination variations }\end{array}$ & $\begin{array}{l}\text { In this proposed approach, the } \\
\text { computational time is almost equal } \\
\text { to the other algorithms. }\end{array}$ \\
\hline 61 & $\begin{array}{l}\text { Efficient visual tracking using particle filter with } \\
\text { incremental likelihood calculation [13] }\end{array}$ & $\begin{array}{l}\text { Authors proposed an efficient MCMC-based visual } \\
\text { tracking algorithm that incorporated the } \\
\text { incremental likelihood function calculation. This } \\
\text { incremental calculation includes not only a } \\
\text { histogram calculation, but also the Bhattacharyya } \\
\text { similarity calculation which improved the } \\
\text { performance of the system. The proposed approach } \\
\text { is very suitable for a particle filter that can be used } \\
\text { on a resource-limited hardware platform }\end{array}$ & $\begin{array}{l}\text { In the proposed approach, the } \\
\text { weight of each particle is calculated } \\
\text { incrementally, while in the } \\
\text { conventional approach, the weight } \\
\text { of each particle is calculated } \\
\text { independently. The authors did not } \\
\text { pay much attention to the tracking } \\
\text { accuracy but focused on the } \\
\text { tracking speed. }\end{array}$ \\
\hline 62 & $\begin{array}{l}\text { Vehicle detection and tracking under various } \\
\text { lighting conditions using a panticle filter [81] }\end{array}$ & $\begin{array}{l}\text { In this paper, authors used four cues including } \\
\text { underneath shadow, vertical edge, symmetry and } \\
\text { taillight are fused for the vehicle detection, The } \\
\text { detection rate is } 92.84 \% \text { even under some difficult } \\
\text { environment and various lighting conditions }\end{array}$ & $\begin{array}{l}\text { In some test cases the detection } \\
\text { results are unsatisfactorily due to } \\
\text { the poor quality of the images of } \\
\text { the data base. }\end{array}$ \\
\hline 63 & $\begin{array}{l}\text { Proposed hardware architectures of particle } \\
\text { filter for object tracking }[82]\end{array}$ & $\begin{array}{l}\text { In this paper, authors proposed three different } \\
\text { architectures for Sequential Importance } \\
\text { Resampling Filter (SIRF) implementation, in } \\
\text { which the results shown the resource reduction and } \\
\text { speed up advantages of the architectures }\end{array}$ & $\begin{array}{l}\text { The authors focused mostly on } \\
\text { reducing the execution time. }\end{array}$ \\
\hline 64 & $\begin{array}{l}\text { Feature-driven motion model-based particle- } \\
\text { filter tracking method with abrupt motion } \\
\text { handling [83] }\end{array}$ & $\begin{array}{l}\text { A feature-driven (FD) motion model-based features } \\
\text { from accelerated segment test (FAST) feature } \\
\text { matching is proposed in this paper considering the } \\
\text { limitations in handling abrupt motion tracking } \\
\text { problems. }\end{array}$ & $\begin{array}{l}\text { The FD motion model only } \\
\text { employs the location cues for } \\
\text { guiding particle propagation. }\end{array}$ \\
\hline 65 & $\begin{array}{l}\text { Distributed Markov Chain Monte Carlo kernel } \\
\text { based particle filtering for object tracking [24] }\end{array}$ & $\begin{array}{l}\text { Two schemes for pipelining particles under high } \\
\text { performance computing environment, including an } \\
\text { alternative Markov Chain Monte Carlo (MCMC) } \\
\text { resampling algorithm and kernel function are used } \\
\text { for improving efficiency. }\end{array}$ & $\begin{array}{l}\text { In the proposed works, the simple } \\
\text { local scheme suffers from excessive } \\
\text { communication and its sequential } \\
\text { resampling steps. }\end{array}$ \\
\hline
\end{tabular}




\section{CONCLUSIONS}

In this paper, we surveyed the visual object target tracking using particle filter. Visual object target tracking is one of the most integrating areas of computer vision, as it has many applications in our daily life. Many approaches have been proposed in the literature. Particle filters has the ability to represent multimodal distributions where as the Kalman filters, are limited to gaussian probability distributions. From the survey it is observed that particle filters and its variants have shown good performance than traditional methods and are very much suitable to perform visual object tracking in different cluttered and other environments. Various features and classifiers that are used mostly with particle filters are given. It is also found that using the combination of different particle algorithms gave the good performance in tracking and each method has its own advantage when specific tracking conditions are considered in account.

\section{REFERENCES}

[1] M. S. A. Yilmaz, O. Javed, "'Object tracking: A survey'," ACM Computing Surveys, vol. 38, no. 4, 2006.

[2] G. Quesnel, H. Raynal, E. Ramat, and D. Makowski, "Software environments for implementing the particle filter with dynamic models," pp. 2001-2002, 2006.

[3] Bishop and Welch, "An Introduction to the Kalman Filter". 2001.

[4] http://en.wikipedia.org/wiki/Kalman_filter

[5] http://www.cs.bilkent.edu.tr/ ismaila/MUSCLE/M STracker.htm

[6] A. Yilmaz and O. Javed, "Object Tracking : A Survey," ACM Computing Surveys, vol. 38, no. 4, pp. 1-45, 2006.

[7] Z. B. Musa and J. Watada, "Motion Tracking Using Particle Filter," Lecture Notes in Artificial Intellegence, pp. 119-126, 2008.

[8] H. Pistori, "Mice and larvae tracking using a particle filter with an auto-adjustable observation model," Pattern Recognition Letters, vol. 31, no. 4, pp. 337-346, 2010.

[9] D. Forte and A. Srivastava, "Resource-Aware Architectures for Particle Filter Based Visual Target Tracking," 2011.

[10] P. Chen and H. Q. W. W. M. Zhu, "Contour tracking using Gaussian particle filter," IET Image Processing, vol. 5, no. June 2009, pp. 440-447, 2011.

[11] A. Carmi and L. Mihaylova, "Markov Chain Monte Carlo Particle Algorithms for Discrete-Time
Nonlinear Filtering," Monte Carlo Methods Appl, pp. $1-10$.

[12] D. Simon, Optimal State Estimation: Kalman, $H$ Infinity, and Nonlinear Approaches. pp. 1-530.

[13] H. Liu and F. Sun, "Efficient visual tracking using particle filter with incremental likelihood calculation," Information Sciences, vol. 195, pp. 141-153, 2012.

[14] B. Zhang, W. Tian, and Z. Jin, "Joint tracking algorithm using particle filter and mean shift with target model updating," Chinese Optics Letters, vol. 4, no. 10, pp. 4-7, 2006.

[15] B. N. Bevilacqua, "Tutorial: Rao-Blackwell Particle Filtering."

[16] W. Qi, X. Zhang, L. Chao, O. Yuanxin, and S. Hao "A Robust approach for multiple vehicles tracking using layered particle filter," AEUE - International Journal of Electronics and Communications, vol. 65, no. 7, pp. 609-618, 2011.

[17] Z. H. E. Chen, "Bayesian Filtering : From Kalman Filters to Particle Filters, and Beyond VI Sequential Monte Carlo Estimation : Particle Filters," 2003.

[18] N. G. Branko Ristic, Sanjeev Arulampalam, Beyond the Kalman Filter: Particle Filters for Tracking Applications. Artech House, 2003.

[19] S. Simo, “TIME-VARYING SYSTEMS : Discrete-Time Systems," vol. 2, no. C, pp. 20092011, 2011.

[20] M. Milelli, A. P. Printed, and D. Wetterdienst, "Is the particle Filtering Approach Appropriate for Meso-Scale Data Assimiltion."

[21] C. Kreucher, A. O. Hero, K. Kastella, B. Avenue, A. Arbor, P. O. Box, and A. Arbor, "MULTIPLE MODEL PARTICLE FILTERING FOR MULTITARGET TRACKING,”pp. 1-6, 2004.

[22] http://en.wikipedia.org/wiki/Auxiliary_particle_filt er

[23] M. Pitt and N. Shephard, "Filtering via simulation: Auxiliary particle filters," Journal of the American statistical ..., vol. 94, no. 446, pp. 590-599, 1999.

[24] D. Wang, Q. Zhang, and J. Morris, "Distributed Markov Chain Monte Carlo kernel based particle filtering for object tracking," Multimedia Tools and Applications, vol. 56, no. 2, pp. 303-314, Nov. 2010.

[25] R. Chen and J. S. Liu, "Mixture Kalman Filters 1 Introduction," no. 1960, pp. 1-26.

[26] Y. Rui and Y. Chen, "Better proposal distributions: object tracking using unscented particle filter," Proceedings of the 2001 IEEE Computer Society Conference on Computer Vision and Pattern 
Recognition. CVPR 2001, vol. 2, no. 1, pp. II-786II-793.

[27] A. T. Submitted, I. N. Partial, F. Of, T. H. E. Requirements, F. O. R. The, and D. Of, "Robust Visual Tracking for Multiple Targets," 2005.

[28] K. Nummiaro, E. Koller-Meier, and L. Van Gool, "Object tracking with an adaptive color-based particle filter," Pattern Recognition, pp. 353-360, 2002.

[29] J. Ma, C. Han, and Y. Chen, "Efficient visual tracking using particle filter," Information Fusion, 2007 .

[30] P. Li, T. Zhang, and A. E. C. Pece, "Visual contour tracking based on particle filters," vol. 21, pp. 111$123,2003$.

[31] C. Engineering, M. Seminar, and H. Azimian, "Visual Object Tracking Algorithms," 2005.

[32] A. Li, Z. Jing, and S. Hu, "Particle filter based visual tracking with multi-cue adaptive fusion," Chinese Optics Letters, vol. vol 3, 2005.

[33] X. Xu and B. Li, "Rao-Blackwellised particle filter for tracking with application in visual surveillance," Tracking and Surveillance, 2005.

[34] P. Vadakkepat and L. Jing, "Improved Particle Filter in Sensor Fusion for Tracking Randomly Moving Object," IEEE Transactions on Instrumentation and Measurement, vol. 55, no. 5, pp. 1823-1832, 2006.

[35] F. L. Lim, W. Leoputra, and T. Tan, "Nonoverlapping Distributed Tracking System Utilizing Particle Filter," Journal of VLSI Signal Processing, vol. 49, pp. 343-362, 2007.

[36] R. Mottaghi and R. Vaughan, "An integrated particle filter and potential field method applied to cooperative multi-robot target tracking," Auton Robot, vol. 23, pp. 19-35, 2007.

[37] G. U. O. Rong-hua and Q. I. N. Zheng, "An unscented particle filter for ground maneuvering target tracking," Journal of Zhejiang University SCIENCE A, vol. 8, no. 10, pp. 1588-1595, 2007.

[38] C. Shan, T. Tan, and Y. Wei, "Real-time hand tracking using a mean shift embedded particle filter," Pattern Recognition, vol. 40, pp. 19581970, 2007.

[39] S. Sa, "Rao-Blackwellized particle filter for multiple target tracking," Information Fusion, vol. 8, pp. 2-15, 2007.

[40] J. Czyz, B. Ristic, and B. Macq, "A particle filter for joint detection and tracking of color objects," Image and Vision Computing, vol. 25, pp. 12711281, 2007.
[41] J. Li and C. Chua, "Transductive local exploration particle filter for object tracking," Image and Vision Computing, vol. 25, pp. 544-552, 2007.

[42] A. Li, Z. Jing, and S. Hu, "Robust observation model for visual tracking in particle filter," $A E U$ International Journal of Electronics and ..., vol. 61, pp. 186-194, 2007.

[43] A. S. Montemayor, A. Duarte, J. J. Pantrigo, and A. $\mathrm{Sa}$, "Multi-dimensional visual tracking using scatter search particle filter," Pattern Recognition Letters, vol. 29, pp. 1160-1174, 2008.

[44] S. Choi and D. Kim, "Robust head tracking using 3D ellipsoidal head model in particle filter," Pattern Recognition, vol. 41, pp. 2901-2915, 2008.

[45] B. Zhang, W. Tian, and Z. Jin, "Robust appearance-guided particle filter for object tracking with occlusion analysis," International Journal of Electron. Commun., vol. 62, pp. 24-32, 2008.

[46] P. Taylor, J. Ortegon-aguilar, and E. Bayrocorrochano, "Particle filter tracking without dynamics," Applied Bionics , pp. 37-41, 2008.

[47] B. Guo and W. Sun, "Multiple object detection and tracking with pseudo-particle filter," Front. Electr. Electron. Eng. China, vol. 4, no. 2, pp. 115-120, 2009.

[48] B. Sugandi, H. Kim, and J. Kooi, “A moving object tracking based on color information employing a particle filter algorithm," International Symposium on Artif icial Life and Robotics, pp. 39-42, 2009.

[49] Z. Wang, X. Yang, Y. Xu, and S. Yu, "CamShift guided particle filter for visual tracking," Pattern Recognition Letters, vol. 30, no. 4, pp. 407-413, 2009.

[50] W. Zheng and S. Bhandarkar, "Face detection and tracking using a Boosted Adaptive Particle Filter," Journal of Visual Communication and Image ..., vol. 20, no. 1, pp. 9-27, 2009.

[51] W. Lu, K. Okuma, and J. J. Little, "Tracking and recognizing actions of multiple hockey players using the boosted particle filter," Image and Vision Computing, vol. 27, no. 1-2, pp. 189-205, 2009.

[52] C. Liu, P. Liu, J. Liu, and J. Huang, "2D Articulated Pose Tracking Using Particle Filter with Partitioned Sampling and Model Constraints," Journal of Intell Robot Syst, pp. 109-124, 2010.

[53] B. Sugandi, H. Kim, and J. Koi, "A color-based particle filter for multiple object tracking in an outdoor environment," International Symposium on Artif icial Life and Robotics, pp. 41-47, 2010.

[54] S. Ling, Z. Kadim, K. Meng, and M. Kuan, "Hybrid Blob and Particle Filter Tracking Approach for Robust Object Tracking," Procedia Computer Science, vol. 1, no. 1, pp. 2549-2557, 2010. 
[55] I. Chang and S. Lin, "3D human motion tracking based on a progressive particle filter," Pattern Recognition, vol. 43, no. 10, pp. 3621-3635, 2010.

[56] X. Wang and Z. Tang, "Modified particle filterbased infrared pedestrian tracking," Infrared Physics and Technology, vol. 53, no. 4, pp. 280287, 2010.

[57] J. Zhao and Z. Li, "Particle filter based on Particle Swarm Optimization resampling for vision tracking," Expert Systems With Applications, vol. 37, no. 12, pp. 8910-8914, 2010.

[58] L. Jing and P. Vadakkepat, "Interacting MCMC particle filter for tracking maneuvering target," Digital Signal Processing, vol. 20, no. 2, pp. 561$574,2010$.

[59] H. Medeiros, G. Holguín, P. J. Shin, and J. Park, "A parallel histogram-based particle filter for object tracking on SIMD-based smart cameras," Computer Vision and Image Understanding, vol. 114, no. 11, pp. 1264-1272, 2010.

[60] F. Ababsa, "Real-time camera tracking for structured environment using an iterated particle filter," Systems Man and Cybernetics (SMC), 2010 IEEEConference, pp. 3039-3044, 2010.

[61] C.M. Md.ZAHIDUL ISLAM and C.W. L. OH, "An Efficient Multiple Cues Cynthesis for Human Tracking using a Particle Filtering Framework," International Journal of Innovative Computing,Information and Control, vol. 7, no. 6, pp. 3379-3393, 2011.

[62] Z. L. Husz, A. M. Wallace, and P. R. Green, "Tracking With a Hierarchical Partitioned Particle Filter and Movement Modelling," IEEE Transactions On Systems,Man, And Cybernetics, vol. 41, no. 6, pp. 1571-1584, 2011.

[63] K. Qian, X. Ma, X. Dai, and F. Fang, "Improved Rao-Blackwellized particle filter for simultaneous robot localization and person-tracking with single mobile sensor," Journal of Control Theory Applications, vol. 9, no. June 2009, pp. 472-478, 2011.

[64] Z. Hasan, K. Irene, and A. G. Backhouse, "A Robust Particle Filter-Based Method for Tracking Single Visual Object Through Complex Scenes Using Dynamical Object Shape and Appearance Similarity," Journal of Signa Processing Systems, pp. 63-79, 2011.

[65] R. Péteri, "Tracking dynamic textures using a particle filter driven by intrinsic motion information," Machine Vision and Applications, vol. 22, pp. 781-789, 2011.

[66] A. Ortiz, J. Antich, and G. Oliver, "A particle filter-based approach for tracking undersea narrow telecommunication cables," Machine Vision and Applications, vol. 22, pp. 283-302, 2011.
[67] J. Martínez-del-rincón, C. Orrite, and C. Medrano, "Rao - Blackwellised particle filter for colourbased tracking," Pattern Recognition Letters, vol. 32, pp. 210-220, 2011.

[68] L. Raskin, M. Rudzsky, and E. Rivlin, "Dimensionality reduction using a Gaussian Process Annealed Particle Filter for tracking and classification of articulated body motions," Computer Vision and Image Understanding, vol. 115, no. 4, pp. 503-519, 2011.

[69] H. Han, Y. Ding, K. Hao, and X. Liang, "An evolutionary particle filter with the immune genetic algorithm for intelligent video target tracking," Computers and Mathematics with Applications, vol. 62, no. 7, pp. 2685-2695, 2011.

[70] J. Jose and A. S. Montemayor, "Heuristic particle filter: applying abstraction techniques to the design of visual tracking algorithms," Expert Systems, vol. 28, no. 1, pp. 49-69, 2011.

[71] H. Kubota, M. Takeshi, and H. Saito, "3D head pose tracking using a particle filter with nose template matching," Electronics and Communications in Japan, vol. 94, no. 1, pp. 1447-1454, 2011.

[72] R. Cabido, A. S. Montemayor, and J. J. Pantrigo, "High performance memetic algorithm particle filter for multiple object tracking on modern GPUs," Soft Computing, vol. 16, no. 2, pp. 217 230, May 2011.

[73] R. Paper, C. Songxiao, W. Xuanyin, and X. Ke, "Visual Object Servo Tracking Based on the Particle Filter Method Using a Pan-Tilt-Zoom Camera," International Journal of Advanced Robotic Systems, vol. 9, 2012.

[74] D. T. Cong, F. Septier, C. Garnier, L. Khoudour, and Y. Delignon, "Robust Visual Tracking Via Mcmc-Based Particle Filtering," IEEE International Conference on Acoustics, Speech and Signal Processing, Kyoto : Japan, pp. 2-5, 2012.

[75] M. Sun and C. Shi, "Application of particle filtering in visual tracking," Advanced Materials Research, vol. 485, pp. 207-212, 2012.

[76] J. A. Brown, D. W. Capson, and S. Member, “A Framework for 3D Model-Based Visual Tracking Using a GPU-Accelerated Particle Filter," Ieee Transactions On Visualization And Computer Graphics, vol. 18, no. 1, pp. 68-80, 2012.

[77] N. V. Samarjit Das, Amit Kale, "Particle FilterWith a Mode Tracker for Visual Tracking Across Illumination Changes," Ieee Transactions On Image Processing, vol. 21, no. 4, pp. 2340 2346, 2012.

[78] I. Introduction, "An Optimization-Based Parallel Particle Filter for Multitarget Tracking," Ieee 
Transactions On Aerospace And Electronic Systems, vol. 48, no. 2, pp. 1601-1618, 2012.

[79] P. Li, “An Efficient Particle Filter - based Tracking Method Using Graphics Processing Unit ( GPU )," Journal of Signa Processing Systems, pp. 317-332, 2012.

[80] M. Ho, C. Chiang, and Y. Su, “Object tracking by exploiting adaptive region-wise linear subspace representations and adaptive templates in an iterative particle filter," Pattern Recognition Letters, vol. 33, no. 5, pp. 500-512, 2012.

[81] Y. C. S. Huang and L. F. P. Hsiao, "Vehicle detection and tracking under various lighting conditions using a particle filter," IET Intelligent Transport Systems, no. May 2011, pp. 1-8, 2012.

[82] H. A. A. El-halym, I. I. Mahmoud, and S. E. D. Habib, "Proposed hardware architectures of particle filter for object tracking," EURASIP Journal on Advances in Signal Processing, pp. 119, 2012.

[83] W. Wang and B. Wang, "Feature-driven motion model-based particle-filter tracking method with abrupt motion handling," Optical Engineering, no. 51, p. 4, 2012.

Mr.G.Mallikarjuna Rao is currently working as scientist ' $E$ ' in Research Centre Imarat (RCI), Defense Research Development Organisation. He has 13 years of experience. His research interests include Target Tracking, Image processing, Digital Control Systems, Pattern recognition and Signal Processing. He guided several M.Tech and B.Tech Projects.

Dr. Ch. Satyanarayana is Professor in Computer science and Engineering Department at Jawaharlal Nehru Technological University Kakinada, Kakinada. He has 13 years of experience. His area of interest is on Image processing, Database Management Systems, Speech Recognition, Pattern recognition and network security. He published more than 23 research papers in international journals. He published more than 30 research papers in international conferences. 